\title{
Article
}

\section{Money, Sex, and Drugs: A Case Study to Teach the Genetics of Antibiotic Resistance}

\author{
Karen A. Cloud-Hansen, ${ }^{*+}$ Jason N. Kuehner, $^{+\ddagger}$ Lillian Tong, ${ }^{\S}$ Sarah Miller, ${ }^{*}$ and \\ Jo Handelsman*
}

*Wisconsin Program for Scientific Teaching, Department of Bacteriology, ${ }^{\ddagger}$ Cellular and Molecular Biology Program, and ${ }^{\S}$ Center for Biology Education, University of Wisconsin-Madison, Madison, WI 53706

Submitted December 6, 2007; Revised March 14, 2008; Accepted March 20, 2008

Monitoring Editor: Debra Tomanek

\begin{abstract}
The goal of the work reported here was to help students expand their understanding of antibiotic resistance, the Central Dogma, and evolution. We developed a unit entitled "Ciprofloxacin Resistance in Neisseria gonorrhoeae," which was constructed according to the principles of scientific teaching by a team of graduate students, science faculty, and instructors. A variety of activities and assessments were used, including a case study, short lectures, and group problemsolving. Implementation of "Ciprofloxacin Resistance in Neisseria gonorrhoeae" in a college freshman seminar suggests these materials are useful in increasing understanding of complex biological topics and improving problem-solving abilities.
\end{abstract}

\section{INTRODUCTION}

"Ciprofloxacin Resistance in Neisseria gonorrhoeae" was developed to introduce college freshmen without a declared major to important concepts in biology within a real-world context and to increase their content knowledge and critical-thinking skills. The main question driving development of this unit was whether engaging students in answering complex biological questions increased their understanding of biological principles, such as the Central Dogma of molecular biology, mutation, evolution, natural selection, and antibiotic resistance. We used the problem of antibiotic resistance in Neisseria gonorhoeae and the societal questions linked to the epidemiology and treatment of gonorrhea because it requires understanding of fundamental biological concepts and raises issues about money, sex, and drugs, combining biological content with civic engagement.

How antibiotics work is not well understood by the general public. For example, a survey of 7120 adults in the United Kingdom revealed that $38 \%$ did not know that antibiotics are ineffective against most coughs and colds,

DOI: $10.1187 /$ cbe. $07-12-0099$

${ }^{+}$These authors contributed equally to this work.

Address correspondence to: Karen A. Cloud-Hansen (kach@bact. wisc.edu). while $43 \%$ did not know that "antibiotics can kill the bacteria that normally live on the skin and in the gut" (McNulty et al., 2007). Improving middle school students' and soldiers' understanding of the biology underlying transmission of sexually transmitted diseases (STDs) also improves their ability to identify the risk factors associated with acquiring an STD (Yaren et al., 2004; Zamora et al., 2006). Thus, improved understanding of the biological content covered in this unit is important in addressing a variety of public health concerns.

Improved comprehension of the major themes of biology addressed in "Ciprofloxacin Resistance in Neisseria gonorrhoeae" is also important for general scientific literacy. According to studies by Miller and colleagues, one in three American adults firmly rejects the concept of evolution (Miller et al., 2006), partially based on misconceptions about the theory of evolution and data supporting it. Directly engaging students' misconceptions and prior knowledge has been shown to be important in improving their understanding of commonly misunderstood topics including evolution (Verhey, 2005). The rationale behind having students solve real-world problems to increase their subject matter comprehension and critical-thinking skills is discussed in-depth in The Power of Problem-Based Learning (Duch et al., 2001).

A scientific teaching approach was used to address multiple learning goals (Table 1) and incorporate a variety of activities to engage a diverse student population in learning. The emphasis 
of the scientific teaching approach is to infuse the classroom with the critical thinking, rigor, and creativity common to experimental research (Handelsman et al., 2007). As part of scientific teaching, we used methods previously shown to improve student learning (reviewed in Handelsman et al., 2004; Handelsman et al., 2007). We supplemented short lectures with active-learning exercises in which students discover knowledge and develop critical-thinking skills. A parallel scientific process was used to plan, assess, and revise the instructional materials (see Chapter 5, Handelsman et al., 2007).

The primary activity for the unit immersed students in a complex and current scientific problem. Students were given a case study in which they must decide how best to address the emergence of ciprofloxacin-resistant gonorrhea. The case crossed several disciplines and stimulated-consideration of scientific, political, and socioeconomic issues. Multiple types of resources were available for the students to solve the case, including research articles, websites, computer animations, and podcasts. (All materials for this unit, including lecture notes, slides, and activities are posted on the Scientific Teaching Digital Library at http://scientificteaching. wisc.edu/materials in the Molecular Biology section.) The case was the cornerstone of the entire unit, in which students learn about the Central Dogma of molecular biology, mutation, evolution, natural selection, and antibiotic resistance. Through active-learning exercises and group problem solving, students were exposed to content information and addressed misconceptions in the field. This article describes construction of the unit using a scientific teaching approach, implementation of the materials in a freshman seminar, evaluation of student learning gains, and discussion of other applications of these materials.

\section{MATERIALS AND METHODS}

\section{Course and Student Background}

This unit was designed for "Ways of Knowing Biology," an introduction to biological research for freshmen at the University

Table 1. Alignment of unit learning goals, activities, and assessments

\begin{tabular}{|c|c|}
\hline Day & Learning goal \\
\hline \multicolumn{2}{|c|}{ Pre-unit } \\
\hline 1 & $\begin{array}{l}\text { Students will understand the } \\
\text { fundamentals of gene expression and } \\
\text { how changes in genotype can perturb } \\
\text { phenotype (Essential). Students will } \\
\text { understand that antibiotic resistance } \\
\text { is a predictable consequence of } \\
\text { natural selection, but steps can be } \\
\text { taken to delay the process } \\
\text { (Important). Students will know the } \\
\text { prevalence of antibiotic resistance at } \\
\text { a national and local level and how } \\
\text { experts from different fields are } \\
\text { addressing the problem (Illustrative). }\end{array}$ \\
\hline
\end{tabular}

Activity/assessment of learning outcomes

Online pre-unit survey (Due before Day 1)

Watch video and discuss antibiotic resistance misconceptions. In-class Assessment: What's wrong with this statement? Students will be able to correct common misconceptions about antibiotic resistance and evolution. Introduction of case study. Mini-lecture: Antibiotic targets and the molecular basis of evolution, Central Dogma. Inclass Assessment of Learning Outcome: Strip sequence. Students will be able to construct the flow of genetic information from DNA to RNA to protein and list the potential outcomes of a DNA replication error. Mini-lecture: Evolution of antibiotic resistance.

Mini-lecture: Gonorrhea prevalence, mechanism of ciprofloxacin antibiotic resistance. In-class Assessment: Oneminute paper and strip sequence. Students will be able to correctly order the stages of gene expression and explain how a genetic mutation could alter an antibiotic target. In-class Assessment: Group discussion of gonococcal isolate surveillance project (GISP) and its limitations. Students will be able to collaborate with a group to identify populations at high risk for acquiring antibiotic-resistant gonorrhea and provide a rationale for selection of patient samples to monitor.

Case Study: Students will be able to collaborate with a group to formulate a solution to a case study concerning the treatment of antibiotic-resistant gonorrhea.
Listen to podcast about prevalence of gonorrhea and antibiotic resistance on UW campus

Browse online resources and discuss case report outline with group

Finish case report and online postquiz 
of Wisconsin (BIO 150, http://wiscinfo.wisc.edu/cels/wok/ index.html). The 74 students met once a week for $50 \mathrm{~min}$ and were graded on a pass/fail system. The overarching goal of the course is to help freshmen appreciate how the research process contributes to understanding biology.

\section{Topic Selection and Unit Development}

Design of this unit was a collaboration among graduate students studying disease mechanisms in Neisseria gonorrhoeae and transcription regulation, science education program coordinators, and professors of genetics, bacteriology, and biochemistry. Additional input was provided by other students developing instructional materials. The process of instructional materials development and the underlying teaching and learning philosophy are described in Scientific Teaching (Handelsman et al., 2007) and Understanding by Design (Wiggins and McTighe, 1998). Once learning objectives for the unit were identified (Table 1), a specific topic was selected and the unit was constructed. Considerations in selecting a topic were: (1) illustration of multiple scientific principles, (2) connection to current research, and (3) interest to students. Ciprofloxacin resistance in $N$. gonorrhoeae fit these considerations and the research background of the developers. We thought sexually transmitted disease would be a provocative topic that would keep students focused on the learning objectives. The case study was piloted in fall 2004 in a similar introductory biology seminar course for freshmen at the University of Wisconsin, "Exploring Emerging Issues in Genetics." Other unit aspects were piloted as well through the Wisconsin Program for Scientific Teaching (http://scientificteaching.wisc.edu), including the Gonococcal Isolate Surveillance Project (GISP) problem, the video "A Tiny World," and the antibiotic resistance misconceptions worksheet (adapted from "Bacteria Really Do Rule!," Laurieann Casey [http://scientificteaching.wisc.edu/materials], based on a cartoon by Dianne Anderson and Kathleen Fisher [www.biology lessons.sdsu.edu/cartoons/30_antib.pdf]).

\section{Classroom Activities}

"Ciprofloxacin Resistance in Neisseria gonorrhoeae" was presented over a 3-wk period (see Table 1). Students were expected to complete research and work as a group outside of class to write a case solution. The class was randomly divided into groups of five to six students who were asked to sit together in the auditorium. Day 1 began by addressing misconceptions about antibiotic resistance. The class watched a video, "A Tiny World," in which people on the street are asked questions including "Would you take antibiotics for a cold?" and "Why aren't antibiotics as effective today as they once were?" Students then individually completed a worksheet containing the following "correct the statement" exercise:

Listed below are a question and four erroneous answers. Determine what is incorrect about the statements and write in the space provided. Why aren't antibiotics as effective as they used to be? (1) People have become immune to antibiotics. (2) Antibiotics are changing and consequently becoming weaker. (3) Bacteria have mutated to become resistant. (4) Antibiotics have caused resistance by mutating bacteria.

After working by themselves, students discussed their answers with their groups and reached a consensus. Discussion of the consensus answers served as an introduction to a 20-min mini-lecture on antibiotic functions, the molecular basis of antibiotic resistance, and the Central Dogma of molecular biology. Students' understanding of gene expression was then assessed; the groups were asked to complete an exercise in which they arranged the terms mutation, DNA replication, transcription, and translation in the proper sequential order. Answers were recorded on a sheet of paper and held up for the instructor to view. A second mini-lecture described mutation and natural selection as the basis for the evolution of antibiotic-resistant bacterial strains. After the mini-lecture, the students worked again with their groups to correct the misconceptions they originally identified in the video and on the worksheet and then shared their answers with the class. As homework, the stu- dents listened to a podcast interview with Craig Roberts, a Clinical Assistant Professor at University Health Services clinic, that focused on the prevalence of antibiotic-resistant gonorrhea on the University of Wisconsin-Madison campus.

On Day 2, a mini-lecture was presented on mechanisms of ciprofloxacin resistance and symptoms and incidence of gonorrhea. Students wrote short answers to questions posed by the instructor ("At what stage(s) in the flow of genetic information from DNA to RNA to protein does ciprofloxacin act?" and "What is the result of treating bacteria with ciprofloxacin?") to determine whether they understood how ciprofloxacin functions. Then, they repeated the activity ordering the stages of gene expression from Day 1, but this time the example of a mutation in the gyrA gene (encoding DNA gyrase) and the phenotype of ciprofloxacin resistance was given. Students discussed their answers to both activities with their groups and then the class.

To introduce the case study, each group worked on a problem to detail the limits and biases of the GISP, which is the study protocol the Centers for Disease Control and Prevention (CDC) uses to monitor antibiotic resistance in N. gonorrhoeae (www.cdc.gov/std/ gisp/). Students wrote their responses individually, then discussed their ideas with their group and the class. Students noted that the GISP study design excludes women and patients not attending public health clinics in large cities. By determining the problems inherent in the CDC's strategy for monitoring antibiotic-resistant $N$. gonorrhoeae infections, students gained familiarity with questions they would explore further in the case study.

The centerpiece of the unit was a case study: "You run a public health clinic in Racine, Wisconsin. One of the county commissioners overseeing your clinic is an epidemiologist and wants to know how you plan to address the emergence of ciprofloxacin resistance in Neisseria gonorrhoeae. State budget cuts mean you cannot afford to give all your patients more expensive antibiotics or do all the lab tests you would like. Develop a plan to address the medical, economic, and political questions your clinic will face in dealing with ciprofloxacin-resistant Neisseria gonorrhoeae. Provide scientific data to support your conclusions. Work with your group to describe your clinic plan in a 1- to 2-page, referenced written report."

Each student group gathered information about antibiotic resistance in N. gonorrhoeae, epidemiology of gonorrhea, and treatment options for the disease. Based on this information, the groups each formulated a plan to address ciprofloxacin resistance in N. gonorrhoeae as if they directed a public health clinic in Wisconsin. Students critically analyzed information to support their proposed testing strategy and to justify its political and socioeconomic impacts. Each group prepared a 1- to 2- page report with their findings, which was evaluated following the rubric in Table 2.

\section{Assessment}

Each in-class activity was assessed (Table 1), and group work and contributions to class discussion were informally monitored. The following pre- and postunit survey was conducted anonymously via a web-based survey tool (Zoomerang) to measure student confidence and knowledge with a set of knowledge and skill questions and open-ended course content questions (see also Table 3).

1. What is your declared major? If your major is undecided, what major(s) are you considering?

2. Gender

3. Race

4. Explain how genetic information is transferred from DNA to RNA to proteins. Include the terms: DNA replication, transcription, translation.

5. What could be the consequences to this flow of information if a mistake occurs during DNA replication?

6. Why aren't antibiotics as effective in treating disease as they used to be?

7. Please rate your KNOWLEDGE of the following concepts. (none 
Table 2. Case solution rubric

\begin{tabular}{|c|c|c|c|}
\hline Category & Outstanding & Competent & Needs improvement \\
\hline $\begin{array}{l}\text { Identification of } N \text {. gonorrhoeae } \\
\text { strains to be tested for } \\
\text { ciprofloxacin resistance }\end{array}$ & $\begin{array}{l}\text { Method of ciprofloxacin } \\
\text { resistance testing identified } \\
\text { and justification for selection } \\
\text { given } \\
\text { Strain population to be tested } \\
\text { was identified, the choice was } \\
\text { justified, and impacts to } \\
\text { patient treatment discussed }\end{array}$ & $\begin{array}{l}\text { Method described, but no } \\
\text { justification for selection } \\
\text { provided } \\
\text { Strain population identified and } \\
\text { choice justified or treatment } \\
\text { impact discussed }\end{array}$ & $\begin{array}{l}\text { No specific method mentioned } \\
\text { Absence of accurate discussion } \\
\text { concerning reasons for testing } \\
\text { technique selection or impacts } \\
\text { to patient treatment }\end{array}$ \\
\hline
\end{tabular}

- 1 , very low -2 , low -3 , moderate -4 , high - 5, very high - 6 )

a. The role of bacteria in human health

b. The role of evolution in disease epidemics and antibiotic resistance

c. How a change in genotype may perturb phenotype

d. The flow of genetic information from genes to proteins (gene expression)

e. The role of oncogenes in human disease

8. Please rate your SKILL in the following areas. (none - 1, very low -2 , low -3 , moderate -4 , high -5 , very high -6 )

a. Able to work as an effective group member

b. Able to communicate my ideas logically

c. Able to solve difficult problems about microbiology

d. Able to propose hypotheses, analyze data, and draw conclusions

e. Able to consider ethical and societal dilemmas involved with science and technology

9. Explain a mechanism of antibiotic resistance. Provide an example.

10. Postunit only: What changes would you suggest to improve this unit?

11. Enter your student ID number here

12. Are you age 18 or older?

Students were asked to rate their knowledge of the role of bacteria in human health, and the role of oncogenes in disease, evolution, mutation, and gene expression. A rating of 1 corresponded to no knowledge of the concept, and the top rating of 6 corresponded to a very high level of knowledge about the concept. An identical scale was used to rate their skills in group work, communication, and problem solving. The open-ended questions were scored following the rubric in Table 4 and covered gene expression, mutation, and antibiotic resistance. The response rate was $61 \%$ for the preunit survey $(n=45)$ and $49 \%$ for the postunit survey $(n=36)$. The case study responses were assessed by the rubric in Table 2 .

\section{RESULTS}

Of the 74 students in the course, 23 completed both the preand postunit surveys as determined by matching student ID numbers submitted with each survey. These data were analyzed in paired $t$ tests. Students self-reported learning gains

Table 3. Alignment of survey questions to learning goals

Survey questions
that address it

Students will understand the $4,5,7 \mathrm{c}, 7 \mathrm{~d}$

fundamentals of gene expression and how changes in genotype can perturb phenotype.

Students will be able to critically analyze information from a variety of sources to support a position on a complex scientific issue, while also justifying the political and socioeconomic impacts.

Students will understand that antibiotic resistance is a predictable consequence of natural selection, but steps can be taken to delay the process.

Students will understand how a mutation in the gyrA or parC genes of $N$. gonorrhoeae can lead to ciprofloxacin resistance. 
Table 4. Pre-/postunit survey open-ended questions rubric

\begin{tabular}{|c|c|c|c|}
\hline Question & Outstanding & Competent & Needs improvement \\
\hline $\begin{array}{l}\text { Explain how genetic } \\
\text { information is transferred } \\
\text { from DNA to RNA to } \\
\text { proteins. Include the terms } \\
\text { DNA replication, } \\
\text { transcription, translation. }\end{array}$ & $\begin{array}{l}\text { Used all three of the terms } \\
\text { (DNA replication, transcription, } \\
\text { translation) and correctly } \\
\text { associated them with the } \\
\text { synthesis of DNA, RNA, and } \\
\text { proteins. }\end{array}$ & $\begin{array}{l}\text { Used two of the terms and } \\
\text { associated them correctly } \\
\text { with their synthesis } \\
\text { pathway. }\end{array}$ & $\begin{array}{l}\text { Used one or none of the } \\
\text { terms correctly. }\end{array}$ \\
\hline $\begin{array}{l}\text { What could be the } \\
\text { consequences to this flow } \\
\text { of information if a mistake } \\
\text { occurs during DNA } \\
\text { replication? }\end{array}$ & $\begin{array}{l}\text { Discussed how a mutation in } \\
\text { DNA could result in a change } \\
\text { to protein structure. }\end{array}$ & $\begin{array}{l}\text { Mentioned mutation, but did } \\
\text { not describe how this could } \\
\text { affect the protein. }\end{array}$ & Did not mention mutation. \\
\hline $\begin{array}{l}\text { Why aren't antibiotics as } \\
\text { effective in treating disease } \\
\text { as they used to be? }\end{array}$ & $\begin{array}{l}\text { Discussed how bacteria have } \\
\text { acquired antibiotic resistance } \\
\text { through mutation or natural } \\
\text { selection, evolution. }\end{array}$ & $\begin{array}{l}\text { Discussed bacterial resistance, } \\
\text { but failed to mention } \\
\text { mechanism (mutation and } \\
\text { natural selection, plasmid } \\
\text { transfer, etc.). }\end{array}$ & $\begin{array}{l}\text { Associated antibiotic } \\
\text { resistance with people/the } \\
\text { human body. Discussed } \\
\text { viruses instead of bacteria. }\end{array}$ \\
\hline $\begin{array}{l}\text { Explain a mechanism of } \\
\text { antibiotic resistance. } \\
\text { Provide an example. }\end{array}$ & $\begin{array}{l}\text { Mentioned deactivation of } \\
\text { antibiotic, reduced cell } \\
\text { permeability, lowered } \\
\text { concentration of antibiotic } \\
\text { within bacterium, or alteration } \\
\text { of drug target. Mentioned } \\
\text { ciprofloxacin, penicillin, or } \\
\text { another antibiotic. }\end{array}$ & $\begin{array}{l}\text { Mentioned one of the } \\
\text { mechanisms or provided an } \\
\text { example. }\end{array}$ & $\begin{array}{l}\text { Mentioned mutation, but did } \\
\text { not provide context. }\end{array}$ \\
\hline
\end{tabular}

$(p \leq 0.05)$ in all knowledge categories (Figure 1). Four of these categories (role of bacteria in human health $[p<0.01]$, role of evolution in disease epidemics and antibiotic resistance $[p<0.001]$, how a change in genotype may perturb phenotype $[p<0.01]$, and gene expression $[p<0.01])$ aligned with the major learning goals of the unit (Table 3). Knowledge category \#5, "the role of oncogenes in human disease," was not covered in the unit and was included as a negative control. Learning gains were also reported in this category $(p<0.05)$, but the average knowledge ratings in this category increased from "very low" (preunit survey) to "low" (postunit survey) as compared with ratings of "low" (preunit) and "moderate" (postunit) for the other categories (Figure 1A).

Learning gains were also self-reported in one of the five skill categories, "the ability to solve difficult problems about microbiology" ( $p<0.001$; Figure 1B). Student ratings for the rest of the skill categories were relatively unchanged through the course of the unit; however, students were more confident in these general communication and group work skills. The average preunit survey rating for these categories was "moderate" or "high" (Figure 1B), leaving little room for improvement. Analyzing all survey data or using the Wilcoxon Signed Ranks Tests to determine significance did not change which gains were statistically significant in any of the questions (data not shown).

The answers to the open-ended questions concerning gene expression, mutation, and antibiotic resistance in the survey were evaluated following the rubric in Table 4. Any unanswered question or "I don't know" answer was rated "needs improvement." Analysis of these responses did not yield evidence of significant learning gains across the entire sample (data not shown). However, increased understanding was noted in some pairs of matched responses pre- and postunit (Table 5).

The majority of student groups proposed feasible solutions to the case, meeting the outstanding or competent levels in all categories of the rubric (Table 2). Their responses provided additional assessment as all unit learning goals were addressed in the case. The most common solution involved treating low-risk patients with ciprofloxacin and high-risk patients with a more expensive antibiotic to which widespread resistance in N. gonorrhoeae has not been observed. Outstanding student solutions included:

"We feel that adult women, especially those that are pregnant, should have first priority for new treatments" and "Overall, the clinic will prescribe ceftriaxone to those who fit any of the following conditions: (1) Men who have sex with men; (2) Women who have had a male partner who has had sex with another male; (3) Patients whose gonorrhea symptoms persist more than $72 \mathrm{~h}$ after ciprofloxacin dose; (4) Anyone whose infection is likely to have originated in Asia, the Pacific Islands, or the Pacific coastal states of the U.S."

Students presented arguments about the economic, political, and social impacts of their plans. Many felt that funding limitations were forcing them to cut corners in patient care and, in doing so, their plans had to risk missing detection and proper treatment of some cases of ciprofloxacin-resistant gonorrhea. The most often-cited social impact of the plans was the potential for members of high-risk groups to feel discriminated against or stigmatized, and a political concern often mentioned was that funding requests for sexually transmitted disease treatment and safe-sex education could be opposed by proponents of abstinence-only education. 
A

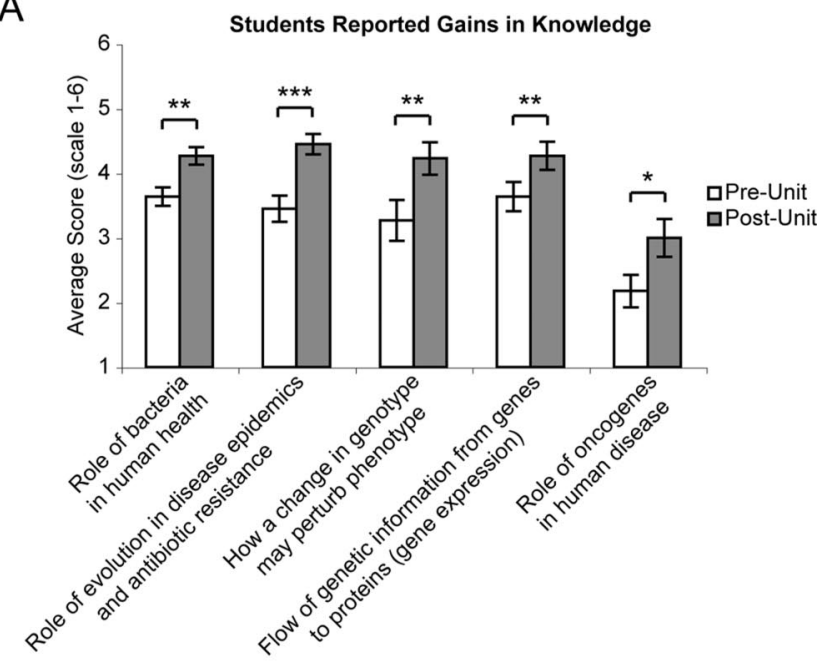

B

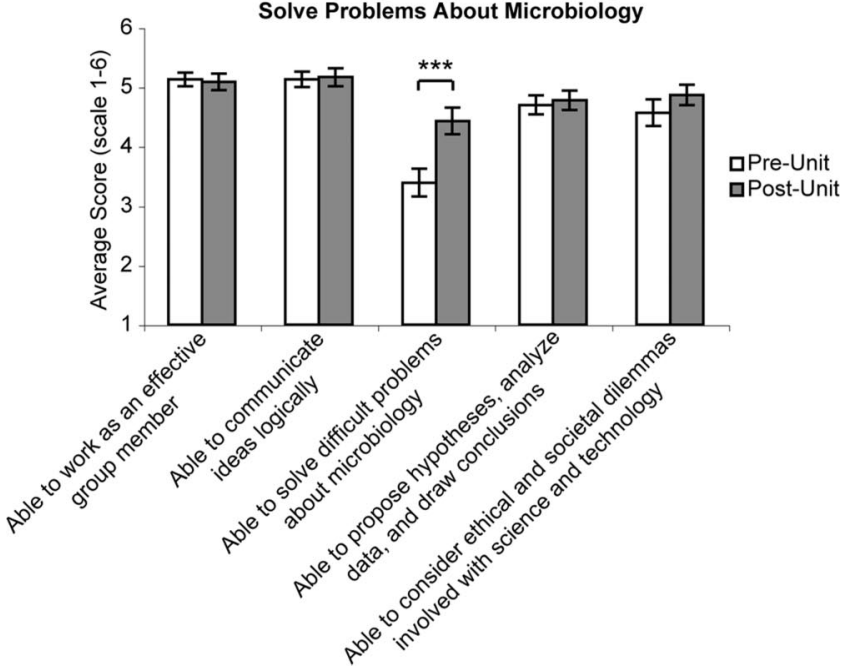

Figure 1. Comparison of pre- and postunit survey results suggests learning gains. (A) Significant learning gains were reported in all knowledge questions asked, including to a lesser degree the question covering oncogenes, which was not discussed in class. A statistically significant difference was seen in the average scores of student-reported knowledge gains pre- and postunit. Twenty-three paired responses were analyzed and the mean score reported. Scores are on a 1-6 point scale with 1 being "none" and 6 being "very high." Error bars indicate SE. An asterisk indicates a statistically significant difference between the means as determined by $t$ tests with one asterisk indicating $p<0.05$, two asterisks indicating $p<0.01$, and three asterisks indicating $p<0.001$. (B) Students reported a gain in the ability to solve difficult problems in microbiology; general group work and data comprehension skills showed no significant change. A statistically significant difference was seen in the average scores of student-reported skill gains pre- and postunit to the question concerning ability to solve difficult problems in microbiology. Twenty-three paired responses were analyzed and the mean score on a 1-6 scale reported. Error bars indicate SE. An asterisk indicates a statistically significant difference between the means as determined by $t$ tests with one asterisk indicating $p<$ 0.05 , two asterisks indicating $p<0.01$, and three asterisks indicating $p<0.001$.

\section{DISCUSSION}

Our driving questions in the design of this unit were: "How can we encourage students to engage with each other and the scientific content?" and "Are the students achieving the learning goals?" Students were encouraged to seek, interpret, and synthesize their own information as much as possible. Students were challenged with a complex problem that was most effectively addressed with a collaborative effort. This teaching unit used a variety of instructional formats to appeal to auditory (e.g., Podcast) and visual (e.g., PowerPoint mini-lectures) learners. In addition, the unit incorporated both individual and group work. Students were, for the most part, willing to participate in active-learning activities or work within a randomly assigned group, though some needed instructor encouragement to do so.

Active learning was incorporated throughout the unit. These activities were interspersed among mini-lectures and gave the students opportunity to apply new information to their existing base of knowledge. The active-learning activities emphasized the key concepts of the mini-lectures and directly confronted common misconceptions about antibiotic resistance, gene expression, and evolution (Table 1). For example, to emphasize the concept that "genotype can perturb phenotype," students conducted a strip sequence exercise in which they arranged the major steps of gene expression into the correct order. A similar exercise was performed with expression of the bacterial gyrA gene and how it relates to the mechanism of the antibiotic ciprofloxacin. Finally, the students determined how the expression of a mutant version of the gyrA gene could result in the phenotype of ciprofloxacin resistance. This activity led into a discussion of the misconception that all mutations cause a change in a protein, alter a phenotype, or are disadvantageous for an organism.

Students self-reported small learning gains in knowledge about oncogenes, the negative control question (Figure 1A). This suggests students may rate their knowledge higher after a learning experience even if the experience did not include the knowledge being assessed. However, their selfassessment of learning gains was higher for knowledge that was included in the unit. The areas in which the most significant gains were reported correspond with the activities presented. During the "What's Wrong with This Statement?" activity, students directly addressed common misconceptions related to the evolution of antibiotic resistance. The "role of evolution in disease epidemics and resistance" displayed the largest learning gain among the knowledge categories. This area was also addressed during the case study activity as students formulated a plan to address the problem of antibiotic-resistant $N$. gonorrhoeae. Likewise, among the skill categories, students demonstrated significant learning gains in their "ability to solve difficult problems about microbiology" (Figure 1B), which they did during the case study and GISP problem. However, in addition to a tendency to overestimate learning gains, completion of a voluntary survey in a one-credit, pass / fail course may be more likely by those students who really enjoyed the content or style of the unit. We did not offer inducements to complete the survey or penalize students' grades if they chose not to provide a response; safeguards against perceived coercion are part of the human subjects protocol. Thus, not all students participated, but we collected and analyzed 23 
Table 5. Sample student responses to open-ended questions

\begin{tabular}{|c|c|c|}
\hline Question & Preunit response & Postunit response \\
\hline $\begin{array}{l}\text { Explain how genetic information is } \\
\text { transferred from DNA to RNA to } \\
\text { proteins. Include the terms DNA } \\
\text { replication, transcription, } \\
\text { translation. }\end{array}$ & $\begin{array}{l}\text { "I don't really know, but I think DNA and RNA } \\
\text { are similar, except DNA is in the nucleus. DNA } \\
\text { is replicated by breaking in half and then } \\
\text { matching up with its opposite amino acids. I } \\
\text { think RNA is made some way in this process. } \\
\text { Proteins are made when mRNA are encoded } \\
\text { by a certain part of the RNA (transcription?), } \\
\text { and go out to make the protein (translation?). } \\
\text { Therefore, I think proteins and RNA are the } \\
\text { same, and mRNA has opposite amino acids." }\end{array}$ & $\begin{array}{l}\text { "DNA is replicated before cell division } \\
\text { so that every cell has its own set of } \\
\text { DNA. RNA is built from DNA } \\
\text { (transcription), and protein is built } \\
\text { from RNA (translation)." }\end{array}$ \\
\hline $\begin{array}{l}\text { Why aren't antibiotics as effective as } \\
\text { they used to be? }\end{array}$ & $\begin{array}{l}\text { "Diseases have developed a genetic resistance to } \\
\text { some antibiotics." } \\
\text { "Bacteria are becoming immune to treatments." }\end{array}$ & $\begin{array}{l}\text { "Bacteria have become resistant." } \\
\text { "Bacteria make physical changes } \\
\text { through random mutations which } \\
\text { doesn't allow the drug to bind to the } \\
\text { specific sites they once did." }\end{array}$ \\
\hline
\end{tabular}

pairs of pre-/postunit surveys. Perhaps the return rate would have been higher in an A-F graded course.

Learning gains were not noted uniformly across the sample of student responses to the open-ended questions included in the survey, though some pairs of matched responses did demonstrate a change in comprehension. Nor were all case solutions outstanding in every aspect measured by the rubric. Thus, although some learning gains were made, uniform achievement of the learning goals was not met by all students. Given the complexity of the topics covered and the range of skills demanded, this is hardly surprising.

The unit developed, "Ciprofloxacin Resistance in Neisseria gonorrhoeae," is adaptable for use in undergraduate discussion or laboratory classes of any level in biology, genetics, microbiology, epidemiology, or public health with few changes. No special equipment is needed for this unit. We provided the students with blank paper and black markers to record their answers to the group activities. However, all activities could be adapted into graded quizzes and worksheets. Instructional technology such as "clickers" could be used for more formalized assessment. The case is openended, as are the solutions. For example, the case could be used to model disease transmission in an epidemiology course or to compare methods of strain typing in a molecular biology course. An instructor could also emphasize course-specific content during the discussion without significantly modifying the materials or change the case question to better mirror course content or current events. For example, students could examine which airline passengers to test after a man diagnosed with extremely drug-resistant tuberculosis travels to Europe for his honeymoon. Additional information on the aligning of cases to course goals can be found in the work of Waterman and Stanley (2005).

In 2007, after the unit was developed, the CDC changed its treatment guidelines for gonorrhea. Because of increased spread of ciprofloxacin resistance in N. gonorrhoeae, only cephalosporins are now recommended to treat gonorrhea (del Rio et al., 2007). However, any of the currently recommended antibiotics can be substituted directly into the case as resistance to spectinomycin (Bala et al., 2005; Su et al.,
2007), and reduced susceptibility to ceftriaxone (Tanaka et al., 2006) and cefixime (Wang et al., 2003) in N. gonorrhoeae have been reported. Instructors should access the CDC treatment guidelines for gonorrhea each year to obtain the latest updates (www.cdc.gov/std/treatment).

"Ciprofloxacin Resistance in Neisseria gonorrhoeae" has the potential to allow students to expand their understanding of antibiotic resistance, the Central Dogma of molecular biology, and evolution by natural selection through a series of active-learning exercises, embedded assessments, supplemental lectures, podcasts, and readings containing actual experimental data and covering a real-world problem with no one correct answer. Materials for this unit are freely available through the Scientific Teaching Digital Library in the "Molecular Biology" category at http://scientificteaching. wisc.edu/materials and could be adapted to meet learning goals in other courses (Writing the Case, 2003).

\section{Accessing Materials}

The supplemental materials mentioned in this article, more information about the materials generated for this case, and information about the scientific teaching approach used to create them can be found at the Scientific Teaching Digital Library at http:/ / scientificteaching.wisc.edu/materials. No registration or password is required to access this site. The library contains the materials mentioned in this paper (categorized as "Molecular Biology") as well as instructional materials on other concepts in biology.

\section{ACKNOWLEDGMENTS}

K. C.-H. and J. K. developed these instructional materials as Howard Hughes Medical Institute Teaching Fellows while participating in the Wisconsin Program for Scientific Teaching. The Wisconsin Program for Scientific Teaching is supported in part by an award from the Howard Hughes Medical Institute Professors Program to J. H (Institutional Review Board protocol \#2006-0516, exempt from review) and by a National Science FoundationCourse, Curriculum, and Laboratory Improvement grant to J. H. and S. M. (Institutional Review Board protocol 2006-0403, exempt from review). Christine Maidl Pribbenow performed some of the statistical analysis of the student learning gains data. We thank 
Allen Laughon for implementing the case in his class and sharing student feedback with us, and we also thank Craig Roberts for his willingness to be interviewed. We thank Brian Asen, David Nelson, Jim Stewart, Jon Woods, and the HHMI Teaching Fellows in Classroom Teaching for their review of these materials.

\section{REFERENCES}

Bala, M., Ray, K., and Salhan, S. (2005). First case of spectinomycin resistant Neisseria gonorrhoeae isolate in New Delhi, India. Sex. Transm. Dis. 81, 186-187.

del Rio et al. (2007). Update to CDC's Sexually Transmitted Diseases Treatment Guidelines, 2006: Fluoroquinolones no longer recommended for treatment of gonococcal infections. MMWR Morb. Mortal. Wkly. Rep. 56, 332-336.

Duch, B. J., Groh, S. E., and Allen, D. E. (eds.) (2001). The Power of Problem-Based Learning, Sterling, Va: Stylus Publishing.

Handelsman, J. et al. (2004). Scientific teaching. Science 304, 521-522.

Handelsman, J., Miller, S., and Pfund, C. (2007). Scientific Teaching, New York: W. H. Freeman and Company.

McNulty, C.A.M., Boyle, P., Nichols, T., Clappison, P., and Davey, P. (2007). Don't wear me out - the public's knowledge of and attitudes to antibiotic use. J. Antimicro. Chemother. 59, 727-738.

Miller, J. D., Scott, E. C., and Okamoto, S. (2006). Science communication: public acceptance of evolution. Science 313, 765-766.

Su, X., Jiang, F., Qimuge, Dai, X., Sun, H., and Ye, S. (2007). Surveillance of antimicrobial susceptibilities in Neisseria gonorrhoeae in Nanjing, China, 1999-2006. Sex. Transm. Dis. 34, 995-999.
Tanaka, M., Nakayama, H., Huruya, K., Konomi, I., Irie, S., Kanayama, A., Saika, T., and Kobayashi, I. (2006). Analysis of mutations within multiple genes associated with resistance in a clinical isolate of Neisseria gonorrhoeae with reduced ceftriaxone susceptibility that shows a multidrug-resistant phenotype. Int. J. Antimicrob. Agents 27, 20-26.

Verhey, S. D. (2005). The effect of engaging prior learning on student attitudes toward creationism and evolution. BioScience 55, 996-1003.

Wang, S. A. et al. (2003). Multidrug-resistant Neisseria gonorrhoeae with decreased susceptibility to cefixime-Hawaii, 2001. Clin. Infect. Dis. $37,849-852$.

Waterman, M., and Stanley, E. (2005). Biological Inquiry: A Workbook of Investigative Cases for Campbell and Reece Biology, 7th ed (Instructor Version), San Francisco: Pearson Benjamin Cummings.

Wiggins, G., and McTighe, J. (1998). Understanding by Design, Alexandria, Va: Association for Supervision and Curriculum Development.

Writing the Case. (2003). http://bioquest.org/lifelines (accessed 1 October 2003).

Yaren, H., Kir, T., Ucar, M., Gocgeldi, E., and Hasde, M. (2004). Training enlisted men on sexually transmitted diseases and preparation of a training model. Mil. Med. 169, 980-984.

Zamora, A., Romo, L. F., and Au, T.K.F. (2006). Using biology to teach adolescents about STD transmission and self-protective behaviors. J. Appl. Devel. Psych. 27, 109-124. 